IZA DP No. 6597

How Well Are Women Represented at the AEA Meeting?

A Study of the 1985-2010 Programs

Rosemary Cunningham

Madeline Zavodny

May 2012 


\title{
How Well Are Women Represented at the AEA Meeting? A Study of the 1985-2010 Programs
}

\author{
Rosemary Cunningham \\ Agnes Scott College \\ Madeline Zavodny \\ Agnes Scott College \\ and IZA \\ Discussion Paper No. 6597 \\ May 2012 \\ IZA \\ P.O. Box 7240 \\ 53072 Bonn \\ Germany \\ Phone: +49-228-3894-0 \\ Fax: +49-228-3894-180 \\ E-mail: iza@iza.org
}

Any opinions expressed here are those of the author(s) and not those of IZA. Research published in this series may include views on policy, but the institute itself takes no institutional policy positions.

The Institute for the Study of Labor (IZA) in Bonn is a local and virtual international research center and a place of communication between science, politics and business. IZA is an independent nonprofit organization supported by Deutsche Post Foundation. The center is associated with the University of Bonn and offers a stimulating research environment through its international network, workshops and conferences, data service, project support, research visits and doctoral program. IZA engages in (i) original and internationally competitive research in all fields of labor economics, (ii) development of policy concepts, and (iii) dissemination of research results and concepts to the interested public.

IZA Discussion Papers often represent preliminary work and are circulated to encourage discussion. Citation of such a paper should account for its provisional character. A revised version may be available directly from the author. 


\section{ABSTRACT \\ How Well Are Women Represented at the AEA Meeting? A Study of the 1985-2010 Programs}

The proportion female in the economics profession in the U.S. has been low historically compared with other disciplines. Although the percentage of Ph.D. degrees awarded to women and the representation of women on faculties have increased over time, economics still lags many other fields. Previous research has documented gender gaps in tenure, promotion and publication, some of which have narrowed over time. This study examines another aspect of women's representation within the economics profession: their participation in a session at the American Economic Association annual meeting. We examine the gender of participants on the program at the 1985-2010 meetings to determine how women's participation at this important venue has changed over the past 25 years. The results show that women's participation has increased over time, particularly since 2002 . However, women appear to be underrepresented on the program relative to other measures of their representation in the profession.

JEL Classification: A1

Keywords: women in economics, economics profession, academic labor market

Corresponding author:

Madeline Zavodny

Department of Economics

Agnes Scott College

141 E. College Ave.

Decatur, GA 30030

USA

E-mail: mzavodny@agnesscott.edu 


\section{How Well Are Women Represented at the AEA Meeting? A Study of the 1985-2010 Programs}

Any process of professional selection that is informal, and whose details are only known or understood by a relatively small in-group, [is] disadvantageous to women, who benefit less frequently than men from sponsorship by more established members of the profession. The process by which sessions at the AEA annual meetings are organized and papers invited has been one of these little-understood processes. (CSWEP annual report, 1985: 452-453)

Every winter, economists gather for the annual meetings of the Allied Social Science Association (ASSA). The annual meetings include sessions organized by about 50 organizations, including the American Economic Association (AEA). The AEA-sponsored sessions are organized by the President-Elect of the AEA from invited and submitted papers. Being on the AEA program gives economists high-profile exposure within the profession and the possibility of publishing their papers in the American Economic Review Papers \& Proceedings May issue. Participating in an AEA session has become more important given the AEA's decision to decrease the number of sessions sponsored by other organizations at the annual meetings (Glenn, 2007).

Concern about underrepresentation of women and of research related to women on the AEA program motivated the Committee on the Status of Women in the Economics Profession (CSWEP) to begin organizing sessions at the annual meetings in 1974. This practice continues to this day. CSWEP currently organizes six sessions for the meetings, three of which usually concern topics related to gender. Papers in CSWEP sessions typically have at least one female author, although junior men can present sole-authored papers in gender-related CSWEP sessions. 
Previous research suggests that women's participation in AEA sessions has increased since the 1970s but there has been little systematic analysis of this issue (Bartlett, 1998). Indeed, only two studies, by Hinshaw and Siegfried (1995) and Bartlett (2009), have examined who is on the AEA program. Both of those studies focused on departmental representation, although Bartlett notes that the percentage of paper presenters who are female was higher in 1993-94 than in 1983-84 and even higher in 2003-04.

This study adds to this small literature a comprehensive examination of the gender composition of participants in the AEA sessions, including the sessions organized by CSWEP, over the 25-year period 1985 to 2010 . We look at all participants as well as various subsets of participants, including those affiliated with U.S. academic institutions, U.S. academic institutions with a top 20 economics department, authors, chairs and discussants.

\section{Background}

There are several reasons why women might be underrepresented on the AEA program relative to their numbers within the profession. First, female economists tend to publish less than male economists (Fish and Gibbons, 1989; Ginther and Kahn, 2004; Hilmer and Hilmer, 2007). Differences in rank of Ph.D. institutions, affiliation and other characteristics may account for this gender gap in publications (Barbezat, 2006; Davis, Huston and Patterson, 2001; Kahn, 1995). Relatedly, female economists are less likely to be at top publishing-intensive departments (McDowell, Singell and Stater, 2006; Barbezat, 1992). In addition, female academics spend more time teaching and less doing research than their male counterparts, on average (Barbezat, 2006; Singell, Lillydahl and Singell, 1996). 
Gender differences in rank and years since Ph.D. could also skew women’s representation on the program if more senior members of the profession are more likely to be on the program. Although the number of female economists at all ranks has increased over time, there is still a substantial decline in the representation of women as one moves up the academic ladder (Ginther and Kahn, 2004; Kahn 1995). In 2010, for example, women accounted for about 28 percent of assistant professors in economics Ph.D.-granting departments, 22 percent of tenured associate professors and 11 percent of full professors (Fraumeni, 2011).

Differences in networks also might lead to gender differences in program participation. Economists are more likely to coauthor with and cite individuals of the same sex (McDowell and Smith, 1992; Ferber, 1988). This might lead to women having smaller networks and reduce their likelihood of participating in the program. However, McDowell, Singell and Stater (2006) generally find that women are not less likely than men to have a coauthored publication, although men do appear to benefit more than women from coauthorship in terms of publication probabilities. In a similar vein, Laband and Tollison (2000) find that women are more likely than men to coauthor within economics, but women are less likely than men to engage in longdistance collaboration.

Women's participation in the AEA program is likely to have risen over time as the number of women at various stages of the pipeline has increased. Fraumeni (2011) documents a clear increase in the female percentage of new Ph.D.s and assistant, associate and full professors from 1985 to 2010. The likelihood that a female Ph.D. economist’s first position is in a top 50 program has increased over time as well (McMillen and Singell, 1994). In addition, gender differences in publications appear to have narrowed over time, which might contribute to increased participation of women in the AEA program. McDowell, Singell and Stater (2004) find 
that women in Ph.D.-granting departments were less likely than men to publish during the 1970s and 1980s but not during the 1990s.

The increase over time in the number of CWEP-organized sessions should have led to an increase in the number of women on the program as well. At the December 1985 meetings, CSWEP sponsored two sessions on gender-related topics. The number of CSWEP-organized sessions increased to three in 1987, to five in 1988 and again to the current number of six in 1989.

More generally, recent research suggests that women face difficulty within the economics profession. Based on an analysis of data from the Survey of Doctoral Recipients and their own sample of economists who were assistant professors in Ph.D.-granting departments in the late 1980s, Ginther and Kahn (2004) conclude that women are less likely than men to get tenure and take longer to do so, even controlling for factors such as number of publications and citations. ${ }^{1}$ McDowell, Singell and Ziliak (1999, 2001) also find evidence of gender differences in tenure and promotion in a sample of AEA members, although these differences appear to have narrowed over time.

\section{Stylized Facts on Women in Economics}

Table 1 provides an overview of women's representation in the economics profession for the years 1985 and 2010, the beginning and end points for this study. The table reports the percentage of new Ph.D.s and the percentage female at various ranks within all Ph.D.-granting departments.

\footnotetext{
${ }^{1}$ Blackaby, Booth and Frank (2005) find evidence of a gender gap in promotion and earnings among academic economists in the U.K.
} 
As noted by the studies discussed above, there has been an increase in women's representation in economics over time. For example, the proportion of new economics Ph.D. recipients who are female rose from 15 percent in 1985 to 33 percent in 2010. The proportion of assistant, associate and full professors who are female at Ph.D.-granting departments also increased substantially during this period. These stylized facts suggest that women’s representation on the AEA program should have increased over time.

\section{Data and Methods}

We examine AEA programs from 1985-2010. ${ }^{2}$ The AEA switched its meetings from December to January in 1992, so those programs cover 25 years of meetings. Our analysis does not include any joint sessions except those organized by CSWEP (which are not marked as such in the program). Most of our analysis focuses on regular sessions, which typically include a chair, three papers and three discussants. We do not include any non-CSWEP-organized sessions labeled in the program as an invited lecture, roundtable, panel, symposium, celebration or the like, or sessions with single speaker, poster sessions or luncheons.

Over the 25 years, a total of 25,532 participants were listed on the AEA preliminary program (not including the special types of sessions described above). There were only 15,145 unique combinations of name and institutional affiliation listed on the programs, indicating that many individuals were on the program multiple times within a year or across years. ${ }^{3}$ As the top two rows in Table 2 report, the number of participants (sessions) increased from 401 (51) in

\footnotetext{
${ }^{2}$ For 1985-1999, we use the preliminary programs published in the American Economic Review. For 2000-2010, we used the printed programs. We thank John Siegfried for providing us with the printed programs.

${ }^{3}$ The calculation of the number of unique combinations of name and institutional affiliation estimates the number of unique individuals only inasmuch as names did not change for reasons such as marriage (or major typographical errors), individuals did not change institutions, and that there is only one person with a particular combination of name and affiliation.
} 
1985 to 1842 (148) in 2010. ${ }^{4}$ This dramatic increase in the number of participants—-359 percent compared with a 190 percent increase in the number of sessions—reflects the growing prevalence of coauthored papers in the economics profession and an increase in the average number of discussants per session.

We attempted to ascertain the gender of every participant in an AEA session. Most individuals' gender is obvious from their first name. ${ }^{5}$ In cases where there was any doubt, we first searched for a website that included a photograph of the participant. We were unable to find a photograph for a small number of participants with gender-ambiguous names, particularly graduate students and people who were on earlier programs but are no longer active in the profession. We then searched for a mention of them on the Internet that included a pronoun. For a few individuals, we contacted a former colleague, another session participant or a dissertation supervisor to ask about gender. We used the website www.behindthename.com, which provides etymologies of names, to assign gender for some foreign names.

We focus our analysis on participants who are affiliated with a U.S. academic institution. As Table 2 shows, we were able to identify gender for 17,989 such participants. We focus on this group because it is most comparable to U.S. economics professors. All else equal, one would expect the representation of women among participants on the AEA program to be similar to their representation in the profession, as proxied by Ph.D. recipients and professors at Ph.D.granting economics departments.

\footnotetext{
${ }^{4}$ Here, and for the remainder of the paper, we use the term "participants" to refer to the number of (non-unique) names listed on the program. An individual who appears twice on a program would be counted as two participants. We think this metric is more relevant than the unique number of participants because it better reflects the number of slots available.

${ }^{5}$ Davis, Huston and Patterson (2001), Ferber (1988), McMillen and Singell (1994) and many other studies use similar methods to classify economists' gender.
} 
A large proportion of participants are affiliated with an academic institution with a top 20 economics Ph.D. program. ${ }^{6}$ During 1985-2010, over 55 percent of program participants are affiliated with an institution with a top 20 department. For comparison, the Survey of Earned Doctorates indicates that the top 20 institutions awarded about 37 percent of all economics Ph.D.s in the U.S. during 1966-2005. Not only are participants affiliated with top programs disproportionately represented on the program, but also the concentration increased over time. The fraction of participants on the AEA program affiliated with an institution with a top 20 department was significantly higher in 2010 (57 percent) than in 1985 (41 percent). For comparison, the top 20 departments accounted for less than 25 percent of all faculty at economics Ph.D.-granting departments in 2010. ${ }^{7}$ Interestingly, women at top 20 programs appear to be overrepresented on the program in 2010; less than 20 percent of all faculty at those programs in 2010 were women.

\section{Representation of Women on the AEA Program}

Across the years we examine, about 20 percent of all program participants and of participants affiliated with a U.S. academic institution are female. This suggests substantial representation of women on the program. In addition, the fractions of program participants who are female are higher in 2010 than in 1985 for most of the categories we examine. However, the

\footnotetext{
${ }^{6}$ We use the affiliations listed on the program. The list of top 20 institutions is based on the 2005 U.S. News graduate school rankings, as used in the 2006 CSWEP report. For simplicity, we use a fixed list over time; there have been only minor changes in which schools included in the U.S. News list. The top 20 departments are MIT, Harvard University, Princeton University, Stanford University, University of Chicago, University of CaliforniaBerkeley, Yale University, Northwestern University, University of Pennsylvania, University of California-San Diego, University of California-Los Angeles, University of Michigan-Ann Arbor, University of WisconsinMadison, University of Minnesota-Twin Cities, California Institute of Technology, Columbia University, University of Rochester, Cornell University, Carnegie Mellon University and New York University.

${ }^{7}$ Based on our count of faculty listed on the webpages of the top 20 departments, as listed in footnote 6, on August 27, 2011, relative to the total number of faculty reported in the 2010 CSWEP annual report.
} 
representation of women on the program has failed to keep pace with gains among the profession as a whole, and the gains in women's participation were at an uneven pace.

Table 3 reports the proportion of program participants who are female for various categories of participants during the period 1985-2010 and at five-year intervals. The proportion of all participants (with known gender) who are female rose from 16.5 percent in 1985 to 25.1 percent in 2010 (row 1). The proportions of participants affiliated with any U.S. academic institution and a U.S. academic institution with a top 20 economics Ph.D. program increased as well (rows 2 and 3). Although substantial, the increases are much smaller than the increase in the fraction of economics Ph.D.s awarded to women or the increases in the fraction of assistant, associate and full professors who are female, as reported in Table 1. Only the increase in the representation of women as discussants on the program is of similar magnitude to the other measures of women's representation in the economics profession.

Table 4 presents the results of a regression of the percentage of various categories of participants who are female on a linear time trend to determine whether the proportions increased significantly increased over the entire 25-year period and various subperiods. The results indicate a statistically significant positive time trend during 1985-2010 for all categories examined here (column 1). The linear time trend is steepest among discussants and flattest among authors.

Although those results suggest rising female participation over time, the increases occurred at an uneven pace. Figure 1 shows the percentages female for all participants with known gender, those affiliated with any U.S. academic institution and those affiliated with a U.S. institution with a top 20 economics Ph.D. program. There are three patterns during the 25-year period: women’s participation increased during 1985-1989, was fairly stagnant during 1990- 
2002 and rose again during 2003-2010. ${ }^{8}$ As reported in column 2 of Table 4, the linear trends were positive for most categories during 1985-1989, although not significantly so. The estimated linear trend is negative for all four categories during 1990-2002, and significantly so for all participants and for authors (column 3). During 2003-2010, the estimated linear trend is positive for all four categories, and significantly so for all participants and for discussants (column 4). The 1990s thus were a lost decade for women in economics in terms of increasing their participation on the AEA program. Women's participation has risen since 2002, most significantly among discussants.

\section{The Role of CSWEP}

CSWEP plays a key role in ensuring that women are included in the AEA program. Across 1985-2010, about 22 percent of all women who participated in the program did so via a session organized by CSWEP. As Figure 2 shows, the percentage of women who participated via a CSWEP session has declined over time. This reflects both increasing participation by women in non-CSWEP sessions and the fact that the number of CSWEP sessions has increased more slowly than the total number of sessions. The number of sessions has increased almost threefold since 1985 while the number of CSWEP sessions has only doubled. The proportion of CSWEPsession participants who are female has stayed fairly constant at about 70 percent over time.

Table 5 reports the percentage of participants who are female with and without CSWEP sessions across 1985-2010. If CSWEP-organized sessions are dropped from the data, the percentage of participants who are female is lower in every category examined here. All of the differences reported in column 3 are significant at the 1 percent level.

\footnotetext{
${ }^{8}$ Chow tests reject the hypothesis that these three periods have equal linear time trends.
} 
Figure 3 shows the percentage of participants affiliated with a U.S. academic institution who are female with and without CSWEP sessions during 1985-2010. The gap narrows slightly over time, or the linear time trend of women's participation is slightly more positive if the CSWEP sessions are dropped from the data. This holds true for all measures of participation examined here except discussants, where the linear time trend is flatter without the CSWEP sessions (not shown).

CSWEP offers an important way for female economists who are not affiliated with a top department to participate in the AEA program. As noted earlier, women at top 20 departments are actually overrepresented on the program relative to their numbers within their departments. As Table 5 shows, the difference in the percentage female between all sessions (with CSWEP) and sessions not including CSWEP sessions is smallest among participants affiliated with institutions with a top 20 program. Figure 2 also reflects the relative non-importance of CSWEP for women at top programs, particularly since the early 1990s.

\section{Conclusion}

In a symposium on reflections on 25 years of CSWEP published in the Journal of Economics Perspectives, Milton Friedman wrote, “The pendulum has probably swung so far that men are the ones currently being discriminated against” (1998: 199). This study provides evidence that this is not yet the case as far as the AEA program is concerned. The proportion female in all of the categories we examine rose significantly during 1985-2010. However, the gains were smaller than for other measures of women's representation in the economics profession. The gains also occurred at an uneven pace, with a decrease in participation during 1990-2002 and an increase since then. The role of CSWEP-organized sessions in ensuring that 
women are represented on the program has declined over time, particularly for women affiliated with institutions with top programs. This partially reflects the fact that the number of CSWEP sessions, which is determined by the AEA, has risen more slowly than the total number of sessions. Given women's continued underrepresentation on the program, boosting the number of CSWEP-organized sessions seems a clear way to ensure that women's participation on the AEA program reflects their numbers in the profession. 


\section{References}

Barbezat, Debra A. 1992. “The Market for New Ph.D. Economists.” Journal of Economic Education 23(3): 262-276.

Barbezat, Debra A. 2006. “Gender Differences in Research Patterns Among PhD Economists.” Journal of Economic Education 37(3): 359-374.

Bartlett, Robin L. 1998. “CSWEP: 25 Years at a Time.” Journal of Economic Perspectives 12(4): 177-183.

Bartlett, Robin L. 2009. “The AEA Annual Program Selection Process and Participation: Institutional Affiliations and Gender.” Paper Presented at 2009 ASSA Meeting, San Francisco, CA.

Blackaby, David, Alison L. Booth, and Jeff Frank. 2005. “Outside Offers and the Gender Pay Gap: Empirical Evidence from the U.K. Academic Labor Market.” Economic Journal 115: F81-F107.

Davis, Joe C., John H. Huston, and Debra Moore Patterson. 2001. “The Scholarly Output of Economists: A Description of Publishing Patterns.” Atlantic Economic Journal 29(3): 341349.

Ferber, Marianne A. 1988. “Citations and Networking.” Gender and Society 2(1): 82-89.

Fish, Mary, and Jean D. Gibbons. 1989. “A Comparison of the Publications of Male and Female Economists.” Journal of Economic Education 20(1): 93-105.

Fraumeni, Barbara M. 2011. "Report of the Committee on the Status of Women in the Economics Profession 2010.” American Economic Review Papers \& Proceedings 101(2): 731-736. 
Friedman, Milton. 1998. “A Comment on CSWEP.” Journal of Economic Perspectives 12(4): 197-199.

Ginther, Donna K., and Shulamit Kahn. 2004. "Women in Economics: Moving Up or Falling Off the Career Ladder?” Journal of Economic Perspectives 18(3): 193-214.

Glenn, David. 2007. “Economists' Group Will Ease Policy Forbidding Discriminatory Language in Job Ads.” Chronicle of Higher Education January 8.

Hilmer, Christiana, and Michael Hilmer. 2007. “Women Helping Women, Men Helping Women? Same-Gender Mentoring, Initial Job Placements, and Early Career Publishing Success for Economics Ph.D.s.” American Economic Review Papers \& Proceedings 97(2): 422-426.

Hinshaw, C. Elton, and John J. Siegfried. 1995. “Who Gets on the AEA Program?” Journal of Economic Perspectives 9(1): 153-163.

Kahn, Shulamit. 1995. “Women in the Economics Profession.” Journal of Economic Perspectives 9(4): 193-205.

Laband, David N., and Robert D. Tollison. 2000. “Intellectual Collaboration.” Journal of Political Economy 108(3): 632-662.

McDowell, John M., Larry D. Singell, Jr., and Mark Stater. 2006. “Two to Tango? Gender Differences in the Decisions to Publish and Coauthor.” Economic Inquiry 44(1): 153- 168.

McDowell, John M., Larry D. Singell, Jr., and James P. Ziliak. 1999. “Cracks in the Glass Ceiling: Gender and Promotion in the Economics Profession.” American Economic Review Papers \& Proceedings 89(2): 392-396.

McDowell, John M., Larry D. Singell, Jr., and James P. Ziliak. 2001. “Gender and Promotion on the Economics Profession.” Industrial and Labor Relations Review 54(2): 224-244. 
McDowell, John M., and Janet Kiholm Smith. 1992. "The Effect of Gender-Sorting on Propensity to Coauthor: Implications for Academic Promotion.” Economic Inquiry 30: 6882.

McMillen, Daniel P., and Larry D. Singell, Jr. 1994. “Gender Differences in First Jobs for Economists.” Southern Economic Journal 60(3):701-714.

Singell, Larry D., Jr., Jane H. Lillydahl, and Larry D. Singell. 1996. “Will Changing Times Change the Allocation of Faculty Time?” Journal of Human Resources 31(2): 429-449. 


\section{Table 1}

Percentage of New Ph.D.s and Professors who are Female at Ph.D.-Granting Economics Departments

\begin{tabular}{lccc}
\hline & 1985 & 2010 & \% change \\
\hline New Ph.D. recipients & 15.1 & 33.3 & 120.5 \\
Assistant professors & 14.6 & 27.8 & 90.4 \\
Associate professors & 7.5 & 21.8 & 190.7 \\
Full professors & 4.2 & 10.7 & 154.8 \\
\hline
\end{tabular}

Note: All figures are percentages. Data for associate and full professors are for tenured professors, and data for assistant professors are for untenured professors. Data for 1985 are from Ginther and Kahn (2004); data for 2010 are from the 2011 CSWEP report. 


\section{Table 2}

Number of AEA Program Participants, Total and 5-Year Intervals

\begin{tabular}{lccccccc}
\hline & Total & 1985 & 1990 & 1995 & 2000 & 2005 & 2010 \\
\hline Number of regular sessions & 2573 & 51 & 61 & 83 & 99 & 102 & 148 \\
Total number of participants & 25,532 & 401 & 515 & 727 & 1014 & 1135 & 1842 \\
Participants with known gender & 25,357 & 401 & 514 & 725 & 1009 & 1132 & 1820
\end{tabular}

Participants with known gender affiliated with a U.S. academic institution

\begin{tabular}{lccccccc}
\hline All & 17,989 & 266 & 371 & 571 & 671 & 806 & 1244 \\
Top 20 department & 9903 & 108 & 179 & 272 & 367 & 432 & 709 \\
Author & 10,477 & 151 & 206 & 339 & 387 & 500 & 810 \\
Discussant & 5390 & 79 & 122 & 170 & 215 & 231 & 316 \\
Chair & 1945 & 36 & 43 & 62 & 69 & 75 & 118 \\
\hline
\end{tabular}

Note: The set of top 20 departments is the same for all years. See footnote 6 for a list of those institutions. 
Table 3

Percentage Female among AEA Program Participants, All Years and at 5-Year Intervals

\begin{tabular}{lcccccccc}
\hline & $\begin{array}{c}\text { All } \\
\text { Years }\end{array}$ & 1985 & 1990 & 1995 & 2000 & 2005 & 2010 & $\begin{array}{c}\text { \% Change } \\
\text { 1985-2010 }\end{array}$ \\
\hline Participants with known gender & 20.3 & 16.5 & 23.7 & 24.1 & 20.2 & 23.3 & 25.1 & 52.6
\end{tabular}

Participants with known gender affiliated with a U.S. academic institution

\begin{tabular}{lllllllll}
\hline All & 20.2 & 15.8 & 22.9 & 24.7 & 18.9 & 21.6 & 25.9 & 63.9
\end{tabular}

$\begin{array}{lllllllll}\text { Top 20 department } \quad 16.2 & 13.9 & 19.6 & 18.8 & 15.3 & 16.7 & 20.5 & 47.2\end{array}$

Author

$\begin{array}{llllllll}20.9 & 15.2 & 22.3 & 24.8 & 19.6 & 21.8 & 26.1 & 71.0\end{array}$

$\begin{array}{lllllllll}\text { Discussant } & 19.0 & 12.7 & 23.8 & 24.7 & 17.7 & 20.8 & 26.3 & 107.5\end{array}$

Chair

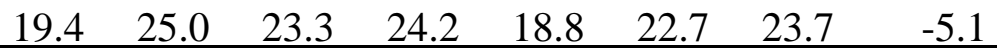

Note: The set of top 20 departments is the same for all years. See footnote 6 for a list of those institutions. 
Table 4

Regression Results for Linear Time Trends in Percentage of Participants who are Female

\begin{tabular}{lllll}
\hline & $1985-2010$ & $1985-1989$ & $1990-2002$ & \multicolumn{1}{c}{$2003-2010$} \\
\hline Participants with known gender & $0.279^{* * *}$ & 0.765 & $-0.387^{* *}$ & 0.486 \\
& $(0.080)$ & $(1.140)$ & $(0.168)$ & $(0.310)$
\end{tabular}

Participants with known gender affiliated with a U.S. academic institution

\begin{tabular}{lcclc} 
All & $0.344^{* * *}$ & 0.497 & $-0.466^{* *}$ & $0.708^{*}$ \\
\multirow{2}{*}{ Affiliated with Top 20 Institution $0.390^{* * *}$} & $(1.139)$ & $(0.177)$ & $(0.322)$ \\
\multirow{4}{*}{ Authors } & $(0.087)$ & $(1.606)$ & $(0.204)$ & $(0.396)$ \\
& $0.280^{* * *}$ & 0.985 & $-0.562^{* * *}$ & 0.884 \\
Discussants & $(0.090)$ & $(1.042)$ & $(0.148)$ & $(0.392)$ \\
& $0.455^{* * *}$ & 0.183 & -0.284 & $0.978^{* * *}$ \\
Chairs & $(0.100)$ & $(0.950)$ & $(0.306)$ & $(0.311)$ \\
& $0.352^{* *}$ & -1.027 & -0.538 & 0.6571 \\
& $(0.150)$ & $(2.756)$ & $(0.439)$ & $(0.424)$ \\
\hline
\end{tabular}

*** $\mathrm{p}<0.01 ; * * \mathrm{p}<0.05 ; * \mathrm{p}<0.1$

Note: Shown are estimated coefficients (standard errors) from OLS regressions of the percentage of program participants with known gender on a linear time trend for the periods indicated. Each coefficient is from a separate regression. 
Table 5

Percentage of Participants who are Female, with and without CSWEP Sessions

\begin{tabular}{lccc}
\hline \multicolumn{2}{c}{ With CSWEP } & Without CSWEP & Difference \\
\hline Participants with known gender & 20.3 & 17.2 & 3.1 \\
\multicolumn{1}{l}{ Participants with known gender affiliated with } & a & & \\
All & 20.2 & 16.9 & 3.3 \\
Top 20 department & 16.2 & 14.8 & 1.4 \\
Author & 20.9 & 17.7 & 3.3 \\
Discussant & 19.0 & 16.1 & 3.0 \\
Chair & 19.4 & 15.2 & 4.2 \\
\hline
\end{tabular}

Note: Shown are the average percentage female of participants with known gender across 1985-2010. 
Figure 1

Percentage of Participants who are Female by Category, 1985-2010

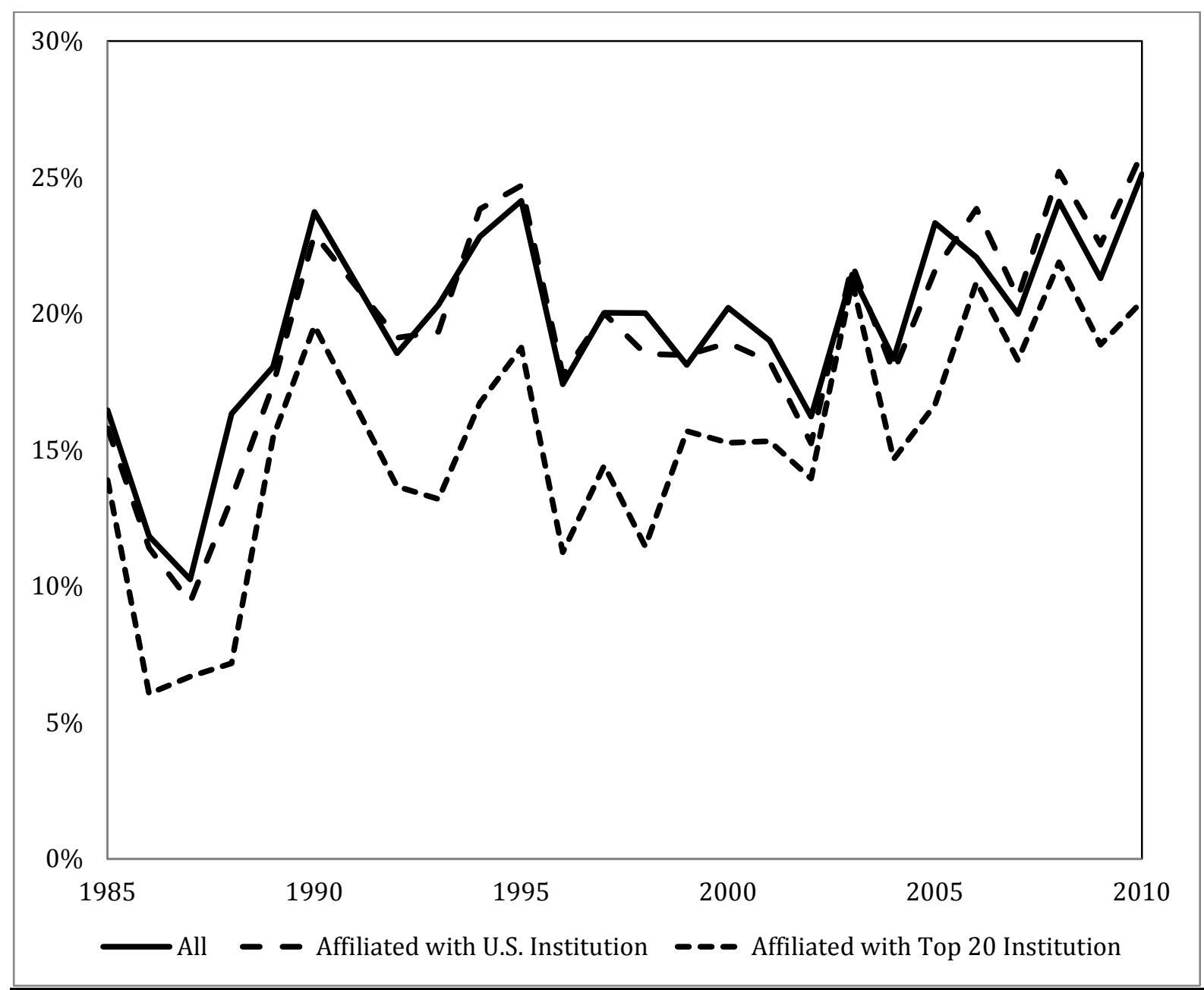


Figure 2

Percentage of Women Participating via a CSWEP Session, 1985-2010

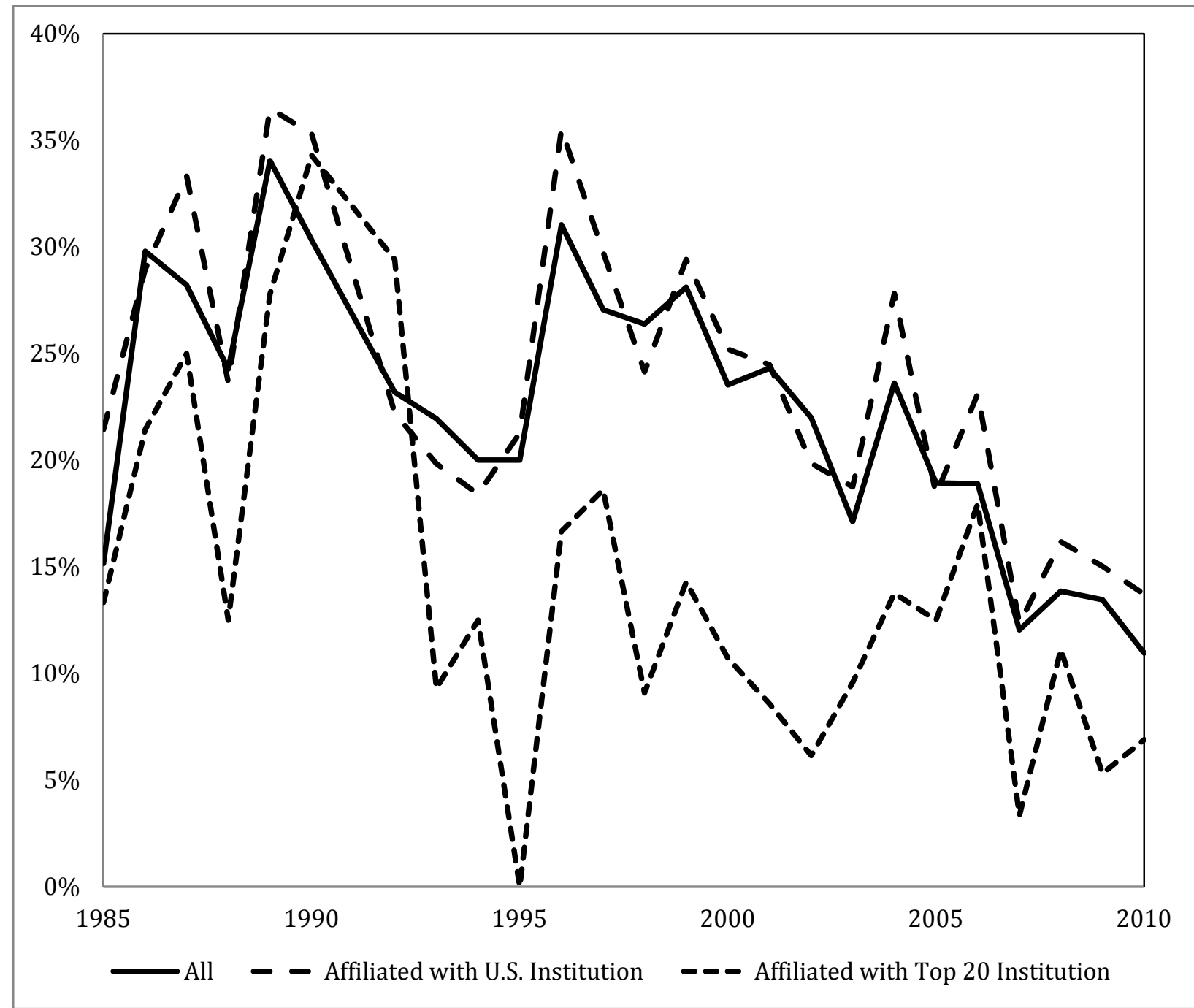


Figure 3

Percentage of Participants who are Female, with and without CSWEP, 1985-2010

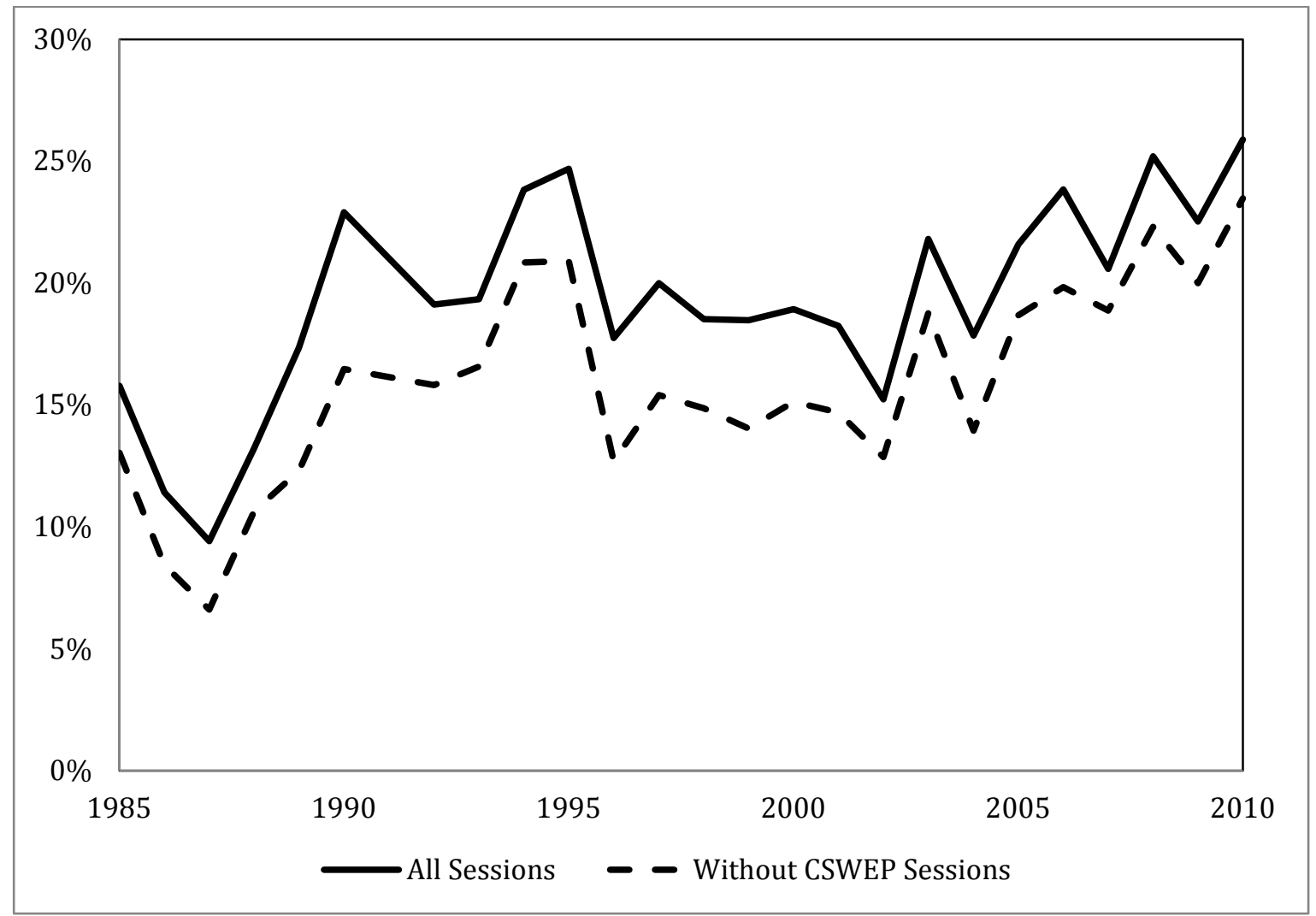

